https://doi.org/10.48009/4_iis_2018_96-105

Issues in Information Systems

Volume 19, Issue 4, pp. 96-105, 2018

\title{
POTENTIAL USAGE OF ARTIFICIAL INTELLIGENCE AND BIG DATA ANALYTICS IN HIGHER EDUCATION ENROLLMENT IN SLOVENIA
}

\author{
Duša Marjetič, Ministry of Education, Science and Sport, dusa.marjetic@gov.si \\ Dušan Lesjak, University of Primorska, Faculty of Management Koper and ISSBS Celje \\ dusan.lesjak@guest.arnes.si
}

\begin{abstract}
In the last 25 years, Slovenia has undergone some major changes in the society, economy and higher education. However, the application and selection procedure for enrollment in higher education which is presented in our work remained unchanged, especially in terms of its characteristics and weaknesses. With the establishment of the national records and analytical information system of higher education in Slovenia, a large amount of data on Slovenian higher education was collected, which enables longitudinal monitoring of students since 2006. Data on the employability of graduates will be added to those on study performance in the next two years. The authors believe that together with existing data on the performance of secondary education and transition to higher education the Artificial Intelligence (AI) and Big Data Analytics (BDA) can be used to manage higher education institutions (HEIs) in terms of curriculum design and that a new approach can also be used in the selection of candidates for studies with an emphasis on optimizing the individuals preferences, taking into account their characteristics - abilities and the range of study programs available.
\end{abstract}

Keywords: Artificial Intelligence, Big Data Analytics, Enrollment, Higher Education, Slovenia

\section{INTRODUCTION}

In the last 25 years, especially after the Bologna reform that took place from 2004 to 2008, Slovenian higher education, as well as the entire society and its economy, has been undergoing major changes which is also reflected in the labor market.

Since 1995, Slovenia has a centralized application and selection procedure for enrollment in the first year of undergraduate studies that is typically based on the secondary school achievements of candidates and their study interest much more than on the characteristics and requirements of individual study programs. HEIs can influence the number and "quality" of students enrolled mainly with the number of enrollment places available - the lesser the number, more higher-quality candidates can be accepted, assuming that there are more candidates than enrollment places available. In other words, HEIs are in most cases (except for arts and sports studies with its entrance exams system) not able to directly influence the selection of candidates, which should be based on their knowledge of the desired or necessary characteristics of the study candidates (based on information on their existing and past students as well as graduates and their employability).

This, of course, results in individuals being admitted and able to enroll in study programs, which may later prove to be of no interest for them or are too demanding and in some cases, they have employability problems later on. The authors are convinced that such an application and selection enrollment procedure should be changed and the HEIs should be given more authority and consequently more responsibility for the selection and enrollment of study candidates. A well-known example of a good practice abroad being entrance exams, candidates' interviews and motivation or written application letters demanded by the HEIs (OECD, 2017).

HEIs could make use of the AI and the BDA, following the lead of the more advanced HEIs already successfully applying it in its management, especially in advising and directing students in their study path, the labor market and its need for the skills and competencies of graduates playing - in addition to the characteristics and students' abilities - an increasing role. 


\section{Issues in Information Systems}

Volume 19, Issue 4, pp. 96-105, 2018

Furthermore, the $\mathrm{AI}$ and the BDA can as well be used even before the candidates make their study decisions, thus before choosing and enrolling in the desired study program, which will also be presented in the this work.

\section{SELECTION PROCEDURE}

\section{Selection procedure for enrollment in undergraduate studies in Slovenia}

In 1995, Slovenia introduced a centralized application and selection procedure for enrollment in the first year of higher education undergraduate studies, which is still in use, remaining almost unchanged. Each year, the procedure begins with the publication of a call for enrollment at the end of January for the upcoming academic year starting from the beginning of October and lasting until the end of September of the following year. The call for enrollment includes the deadlines and procedures for enrollment and a list of study programs with enrollment conditions and selection criteria should there be a limited enrollment. The candidate can submit the application in two (main) application deadlines. The first application deadline takes place in February and March, and the second at the end of August when candidates can apply for remaining enrollment places. Within a single application deadline, the candidate can submit one enrollment application in which he states, in orderly manner, up to three desired study programs. The order of study preferences is important and the candidate can no longer change it after the submission deadline.

Rates for admission to a particular study program are not known in advance and are only determined in the selection process, depending on the number of applications, the candidates results of Sate secondary schools' leaving exam called matura (the term is not translatable into English) and the available enrollment places, which are published simultaneously with the call for enrollment. A successfully passed general matura - a State examination by passing of which an individual obtains an upper secondary school education, enables enrollment in higher education. Enrollment to higher education programs is also possible with the acquired technical upper secondary education, which has since 2001 been completed with a State examination called professional matura. The National Examination Centre is responsible for the preparation of the matura examination at the national level. Matura consists of passing exams related to selected subjects ( 5 in general matura and 4 in professional matura). Each subject consists of an external and internal (oral) part of the assessment, which represents $20-30 \%$ of the total grade of the subject in the general matura whereas in the professional matura the internal rating is much higher, as only two subjects are externally assessed and the internal part represents a $30-40 \%$ of the grade. Examination papers for the external or the written part are encrypted and the assessors do not know the identity of the individual the exam of which is being evaluated. The internal part represents the oral part of the exams or practical assignments performed before the students' high school teachers.

\section{Characteristics of the selection procedure for enrollment}

More than three fifths of first year students enroll in the first application deadline (data valid for the academic year 2016/17). 80,2\% of applications for enrollment within this deadline are submitted by students of the final year of secondary school who do not yet have the results of the matura at the time of application, as they are only to be admitted to the spring examination period in May and June, and the results are published in mid-July. 


\section{Issues in Information Systems}

Volume 19, Issue 4, pp. 96-105, 2018

Table 1. Overview of data on calls for enrollment and the first application deadline for the academic years 1996/97,

\begin{tabular}{|c|c|c|c|}
\hline \multicolumn{4}{|c|}{$2006 / 07$ and $2016 / 17$} \\
\hline Academic year & $1996 / 97$ & 2006/07 & 2016/17 \\
\hline $\begin{array}{l}\text { Number of HEIs included in the call for } \\
\text { enrollment }\end{array}$ & $\begin{array}{l}2 \text { universities } \\
\text { (with } 38 \\
\text { members) } \\
2 \text { independent } \\
\text { HEIs }\end{array}$ & $\begin{array}{l}3 \text { universities (with a } \\
\text { total of } 46 \text { members) } \\
7 \text { independent HEIs }\end{array}$ & $\begin{array}{l}4 \text { universities (with a } \\
\text { total of } 54 \text { members) } \\
13 \text { independent HEIs }\end{array}$ \\
\hline Number of study programs available & 187 & 419 & 473 \\
\hline $\begin{array}{l}\text { Number of study programs with limited } \\
\text { enrollment in the first application } \\
\text { deadline }\end{array}$ & 77 & 122 & 109 \\
\hline Number of study places available & 18.532 & 25.016 & 18.555 \\
\hline \multicolumn{4}{|l|}{ Data for the first application deadline } \\
\hline $\begin{array}{l}\text { Number of applications and share of } \\
\text { applications according to study places } \\
\text { during the first application deadline }\end{array}$ & $19.714(106.4 \%)$ & $26.016(104.0 \%)$ & $15.155(81.7 \%)$ \\
\hline $\begin{array}{l}\text { Number of candidates who met the general } \\
\text { enrollment conditions and their share } \\
\text { according to the study places }\end{array}$ & $14.988(76 \%)$ & $20.645(82.5 \%)$ & $12.532(67.5 \%)$ \\
\hline $\begin{array}{l}\text { Number of accepted candidates and share of } \\
\text { all candidates who met the general } \\
\text { conditions }\end{array}$ & $12.395(83 \%)$ & $17.552(85.0 \%)$ & $11.123(88.6 \%)$ \\
\hline $\begin{array}{l}\text { The percentage of accepted candidates in } \\
\text { the first study preference from all } \\
\text { candidates that met the general conditions }\end{array}$ & $77 \%$ & $68.8 \%$ & $78.4 \%$ \\
\hline $\begin{array}{l}\text { Share of applications submitted by } \\
\text { secondary school graduates }\end{array}$ & $71 \%$ & $61.6 \%$ & $80.2 \%$ \\
\hline
\end{tabular}

Source: University of Ljubljana Higher Education Application and Information Service

The selection procedure of candidates varies according to whether or not the limited enrollment is determined for the study program. The limited enrollment means that the number of applications exceeds the number of study places by $10 \%$ or more. Students who have listed a study program with no limited enrollment as the first study preference of their application are admitted to the study programs if they fulfil the general conditions. In addition to complying with the general conditions, candidates for enrollment to study programs with a limited enrollment must still achieve a sufficient number of points determined in the classification process.

During the classification process, points for each study preference are first calculated, considering the selection criteria that take into account the overall success achieved at the matura or the professional matura, and the general learning achievement from the third and fourth year of secondary school, as well as the achievement in individual matura subjects, determined by study programs, professional matura, and in individual subjects from the third and fourth year of secondary school. When points are attributed to study preference, they are classified into the lists of admitted candidates, according to the number of the points achieved and considering the study preference priorities. Classification takes place simultaneously for all study programs. The list of candidates accepted includes the candidates with the same number of points as the last ranked according to the number of available study places.

Students who do not qualify for enrollment in the program they put as the first preference in their application, are moved to the study program they chose as the second or third preference, according to the same procedure as in the study programs listed in the application as the first preference. 


\section{Issues in Information Systems}

Volume 19, Issue 4, pp. 96-105, 2018

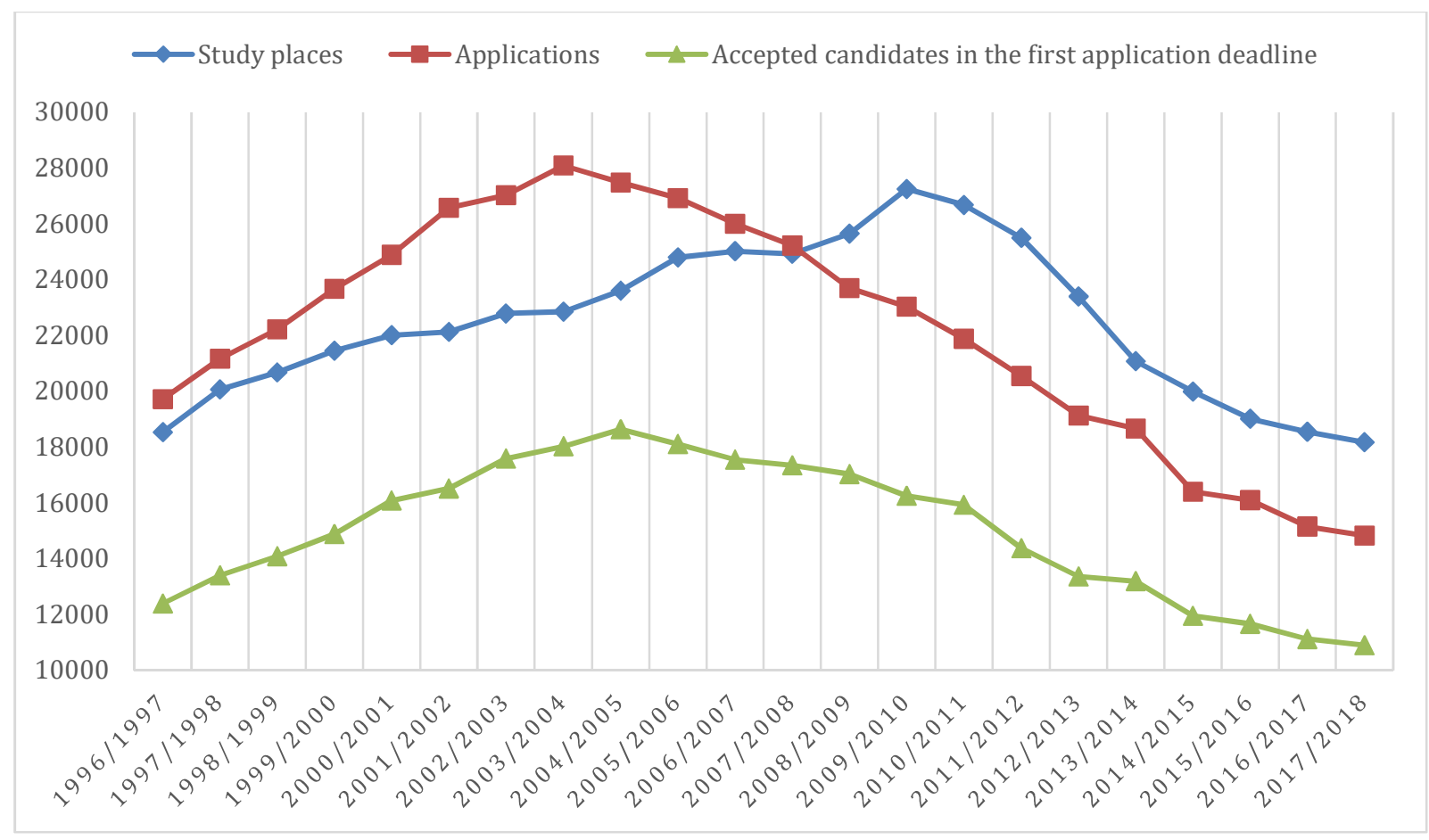

Figure 1. Comparison of the number of available study places and enrollment applications as well as the number of those accepted in the first application deadline for the academic years 1996/97 to 2017/18

Source: University of Ljubljana Higher Education Application and Information Service

In 1995, when the registration and selection procedure was designed, the 18-year-olds from the so-called baby boom generation enrolled in higher education. The number of applications exceeded the offered study places and this trend was maintained until the academic year 2003/04, when the number of applications exceeded the available study places by $22,8 \%$. Since the academic year $2004 / 05$, the number of applications started to decline, while the number of study places continued to increase. The trend of the application surplus reversed in the academic year 2008/09, and with the next year the trend of decreasing study places started as well.

In the last 20 years, the Slovenian higher education environment has changed considerably. In addition to the demographic decline of the population that has been present in higher education since the higher education enrollment for the academic year 2010/11, the Bologna reform has also contributed to the reduction in the total number of university students since it divided the previous undergraduate studies into two levels - the first being the undergraduate and the second being master's degree. New study programs were introduced gradually from the academic year 2005/06 to the academic year 2009/10, when HEIs could only tender the new study programs. 


\section{Issues in Information Systems \\ Volume 19, Issue 4, pp. 96-105, 2018}

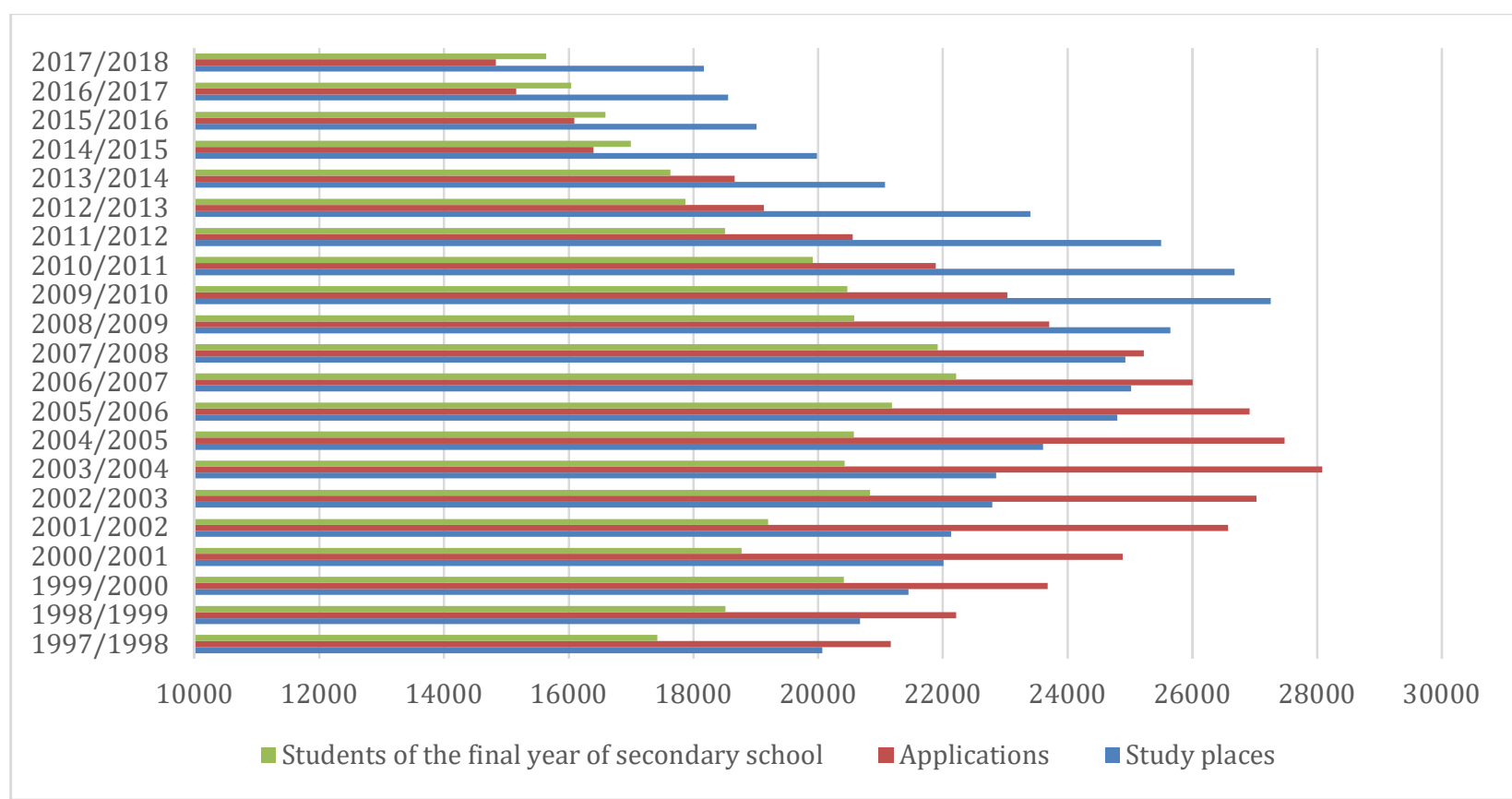

Figure 2. Comparison of the number of available study places and applications for enrollment in the first application deadline with the generation of students enrolled in the final year for the academic years 1997/98 to 2017/18

Source: University of Ljubljana Higher Education Application and Information Service

In 2018, a generation born in 2000, when 18,180 births were recorded, enrolls in higher education. The next major generation of 18-year-olds, which could exceed the available number of higher education study places in 2018 , is expected in 2024, presumably followed by growth until 2028, when the generation 2010 counting 22,343 births, will be enrolling.

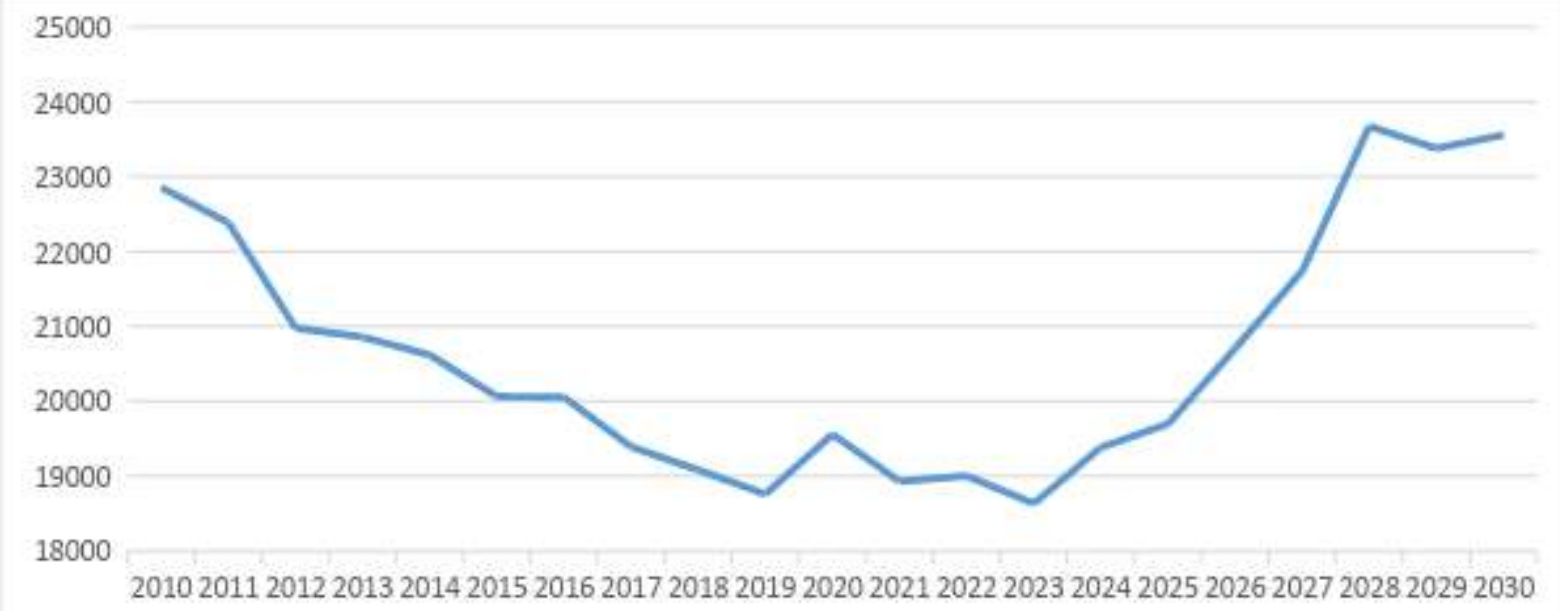

Figure 3. Projection of 19-year-olds in Slovenia

Source: Statistical Office of the Republic of Slovenia

It is evident from the projection of 19-year-olds in Slovenia until 2030 that Slovene HEIs can expect an increase in the number of enrollment candidates, and with the unchanged capacities of Slovenian higher education chances are 


\section{Issues in Information Systems \\ Volume 19, Issue 4, pp. 96-105, 2018}

that the number of applications will once again exceed the number of study places available. However, it should be taken into account that candidates do not apply evenly to all study fields.

The share of candidates applying for study programs with limited enrollment has jumped in academic year 2010/11, this was the second year only Bologna study programs were available and the first year HEIs started to decrease the number of study places. While the share of candidates in study programs with limited enrollment varied between 60,7 and $65,4 \%$, the share of unaccepted candidates into these study programs has increased by 20 percentage points in the last eight years. The reason for these is that the number of these study programs has decreased and that among them is a constant group of study programs (medicine, health care, pharmacy, veterinary, architecture, art academies, preschool education and teaching).

Table 2. Share of study programs with limited enrollment in the first application deadline, the proportion of applicants and rejected candidates

\begin{tabular}{|c|c|c|c|c|}
\hline $\begin{array}{c}\text { Academic } \\
\text { year }\end{array}$ & $\begin{array}{c}\text { Share of study } \\
\text { programs with } \\
\text { limited enrollment } \\
\text { (\%) }\end{array}$ & $\begin{array}{c}\text { The proportion of } \\
\text { applicants applying for } \\
\text { programs with limited } \\
\text { enrollment (\%) }\end{array}$ & $\begin{array}{c}\text { The proportion of } \\
\text { rejected } \\
\text { candidates (\%) }\end{array}$ & $\begin{array}{c}\text { Number of study } \\
\text { programs with } \\
\text { limited enrollment }\end{array}$ \\
\hline $2008 / 09$ & 21.2 & 55.5 & 24.0 & 104 \\
\hline $2009 / 10$ & 19.1 & 53.0 & 26.6 & 103 \\
\hline $2010 / 11$ & 23.7 & 64.6 & 27.6 & 124 \\
\hline $2011 / 12$ & 24.1 & 63.1 & 25.1 & 124 \\
\hline $2012 / 13$ & 22.9 & 62.5 & 38.1 & 118 \\
\hline $2013 / 14$ & 22.9 & 65.4 & 38.8 & 120 \\
\hline $2014 / 15$ & 24.5 & 61.3 & 35.3 & 113 \\
\hline $2015 / 16$ & 21.9 & 65.4 & 42.5 & 109 \\
\hline $2016 / 17$ & 23.0 & 69.7 & 44.8 & 109 \\
\hline $2017 / 18$ & 22.0 & 60.7 & 47.0 & 102 \\
\hline
\end{tabular}

Source: University of Ljubljana Higher Education Application and Information Service

\section{Problems of the application-selection process in undergraduate studies}

For the application-selection procedure, it can be concluded that it is determined by:

- $\quad$ success in individual subjects of the 3rd and 4th years of secondary school and success in (general or professional) matura,

- the enrollment conditions and the selection criteria determined by the study program,

- $\quad$ the order of the prefered study programs at the enrollment application, and

- the algorithm for ranking of the candidates to the list of accepted by study programs.

The conditions for enrollment in undergraduate studies are mostly based on the achievements in secondary education and, except in the field of arts and sports, they are not looking for special talents or other qualities in the candidates, allowing them to compensate for lower grades in matura or in secondary school in the areas for which they may not have been talented or were not a priority to them during their schooling. Therefore, finding out that matura assessment can vary from school to school should be of a great concern. There are great discrepancies in the distribution of achievements in Slovenia when the knowledge at the written part of the matura is assessed externally or when the oral exams and practical skills within the matura frame are assessed by teachers internally. Data show that, as a rule, the excellent achievements of external assessment are lowered by inferior internal grades and vice versa: lower external grades are improved by the highly rated internal parts of the matura (Zupanc et al., 2012). 


\title{
POTENTIAL USAGE OF ARTIFICIAL INTELLIGENCE AND BIG DATA ANALYTICS IN HE ENROLLMENT
}

\begin{abstract}
Artificial Intelligence and Big Data Analytics
The AI could be defined as the ability of machines and systems to acquire and apply knowledge and to carry out intelligent behavior. AI promises to generate productivity gains, improve efficiency of decision making and lower costs, since it allows data processing at enormous scales and accelerate the discovery of patterns. By helping scientist to spot complex cause and effect relationships, AI is expected to contribute to solving complex global challenges, such as those related to the environment, transportation or health AI could radically enhance quality of life, impacting healthcare, transportation, security, justice, agriculture, retail commerce, finance, insurance and banking and of course education. AI could find valuable application wherever intelligence must be deployed (OECD, 2017b). Intelligent systems use combination of the BDA, cloud computing, machine-to-machine communication and the internet of things to operate and learn.
\end{abstract}

The BDA is defined as a set of techniques and tools to process and interpret large volumes of data that are generated by the increasing digitalization of content, the greater monitoring of human activities and the spread of the internet of things. It can be used to infer relationships, establish dependencies, and perform perditions of outcomes and behaviors. Types of BDA are (OECD, 2016):

- Data mining that comprises a set of data management technologies, pre-processing (data cleaning) techniques and analytical methods with the aim of discovering information patterns from datasets.

- $\quad$ Profiling techniques seek to identify patterns in the attributes of a particular entity and classify them.

- Business intelligence tools seek to monitor key operational metrics and create standard reports on a regular basis in the interest of informing management decisions.

- Machine learning encompasses the design, development and use of algorithms that execute a given task while simultaneously learning how to improve its performance.

- Visual analytics are tools and techniques that allow data to be effectively observed, interpreted and communicated through (often interactive) charts and figures).

Recent report made by the AI now urged for a practical framework to assess automated decision systems and to ensure public accountability arguing that if governments deploy systems on human populations without frameworks for accountability, they risk losing touch with how decisions have been made, thus making it difficult for them to identify or respond to bias, errors, or other problems (Reisman et al., 2018).

An important fact is that social-economic data carries with it the history of biases and prejudice existing in society in which the data was created. But this can also present an opportunity for decision makers, who could use the historical data on existing biases and injustices in the system and help reach informed decisions to prevent them in the future.

\section{Artificial Intelligence and Big Data Analytics and HEIs management}

The most obvious way, how AI can affect HE is through courses dealing with AI (Vanderbilt, 2012), than AI definitely affects teaching and learning (Popenici \& Kerr, 2017), (Maderer, 2016) and even assessment of students' achievements (Luckin, 2017) yet HEIs are also turning to AI to help pull data for course recommendations, career path options, administrative assistance and more. It's the processing of data that gives the AI program its power to change HE, since AI is not only able to analyze data from the school, it can analyze data from outside sources as well. Take, for example, market labor data about jobs. The AI platform can pull in that outside data and analyze it to learn what skills employers are looking for in certain career areas. Then it takes information from inside the school to see which classes provide those skills. It makes recommendations not only on what courses will fulfil needs to graduate, but what courses will allow students to learn what they need to pursue the career they want.

Every school has guided pathways - sort of roadmaps that outline how a student would get through the school in a certain number of semesters while earning a specific degree and allowing for some wiggle room with electives. The student can own their own journey but stay within the guardrails of the pathways the HEI has created (Blackwood 2018).

This configuration creates data that can be mined and analyzed for predictive analytics. The AI agent then studies these pathways and learns from them so they can pick up where the school left off and create new, more unique 


\section{Issues in Information Systems}

Volume 19, Issue 4, pp. 96-105, 2018

pathways for students to follow. The AI can create occupation insights that tell students what employers are looking for in certain career paths.

By merging big data with student data and making it easy for administrators to configure it, the groundwork is laid to allow the AI machine to learn. Then the AI can see how students apply to it, how the market changes, and continue to visualize the information for students or respond to students with answers.

Instead of administrators meeting with students and recommending courses, they help inform the AI so that the AI can do so at a more granular and unique level to each student.

This can be taken even further by predicting what grades students will get. The AI can predict grades based on past performance and other performance metrics for each class and use that in the scoring model for at risk students and retention. The AI uses local and outside data to predict how many students will want to take a class. It uses the performance of similar students with similar academic histories to predict how each student will fare in the class. It takes the actual data of how each student performs in the class in order to refine its predictive model and continues to get better through time. Now, the HEIs has vetted information about demand, retention, and performance of every class to visualize for the administration.

\section{Artificial Intelligence and Big Data Analytics and HEIs Enrollment}

As people are more and more aware that the AI can improve students experience and service, can provide students learning analytics, and improve management and organization with delegating administrative coordination and control, supporting complex decisions, design new solutions and provide a second opinion (Sagenmueller, 2017) the AI could help HEIs (and potential students) even sooner by helping in matching the potential students study preferences and capabilities on the one side and HEIs study programs requirements on the other.

In case of Slovene HE, the data on secondary education completion combined with data on HE completion and employment of graduates could be used by HEIs for:

- recommendations to policy makers in the field of education on identified knowledge deficit expected to be gained before entering $\mathrm{HE}$ - secondary education in terms of undergraduate studies,

- $\quad$ self-evaluation and planning of curriculum of HE study programs which development and offer is in a complete autonomy of HEIs, and

- recommendations to candidates for enrollment and students of possible learning paths to reach a desired qualification based on their previous education and on possible employment opportunities in the future.

The authors believe that it is possible and should soon happen that the AI and the BDA would be used even before the candidates actually become students of the desired, but not always the most suitable study program, i.e. at the stage of the selection, application or the admission of the candidate into the desired study program.

One of the key issues that the AI and the BDA could possibly mitigate is that one should be able to shed light on and justify the matching of skills, talents, motives of candidates on one hand, and the characteristics, requirements, promised learning outcomes and the competencies of graduates that the labor market appreciates and needs from individual study programs, on the other. For now, the choice of candidates for most study programs is based primarily on success in secondary education and matura, to which both secondary school students and schools can adapt.

An example, that the AI and the BDA could already have been used in the selection of candidates is as a means of providing a second, supplementary opinion on the suitability of a candidate for a selected study program, where the HEIs could conduct additional interviews with candidates in cases where the opinion of the decision makers regarding the suitability of the candidate for the desired study program would differ from the findings of the AI and the BDA.

\section{CONCLUSION}

Although the technology that enables the processing of large amounts of data in a very short time, which was a prerequisite for the expansion of the AI, has become widely available today, its use in Slovenia has not yet been detected in the management of educational system as well as in the closely related social field. Perhaps one of the 


\section{Issues in Information Systems}

Volume 19, Issue 4, pp. 96-105, 2018

factors contributing to this is the fact that people do not understand the basis on which learning algorithms (sometimes called deep learning) make their decisions (Tufekci \& Rose, 2016).

The practice of advanced HEIs demonstrates how it is possible to use the AI and the BDA in their management, especially in advising and directing students in their study path, with the growing role, besides characteristics - the students' abilities - also of the labor market and its need for the skills and competencies of graduates.

The authors are convinced that the AI and the BDA can also be used even before the candidates make their study preferences that is, before choosing and enrolling in the desired study program. The AI could help HEIs (and potential students) in matching their students' preferences and capabilities and HEIs study programs requirements and by that positively affects efficiency and effectiveness of a higher education system - completion rates and employability of the graduates.

\section{REFERENCES}

Analize prijave in vpisa, pripravila in uredila: Univerza v Ljubljani, Visokošolska prijavno-informacijska služba http://www.mizs.gov.si/si/delovna_podrocja/direktorat_za_visoko_solstvo/sektor_za_visoko_solstvo/statist ika_in_analize_s_podrocja_visokega_solstva/

Blackwood, J. (2018). How One Artificial Intelligence is Changing Higher Education Curriculum, Tech Decision, 23.1.2018, https://mytechdecisions.com/it-infrastructure/artificial-intelligence-higher-educationcurriculum/

Higher Education Act, http://www.svz.gov.si/fileadmin/svz.gov.si/pageuploads/prevodi/List_of_Slovene_laws_and_ regulations_in_English.pdf

Luckin, R. (2017). Towards artificial intelligence-based assessment systems. Nature Human Behaviour, 1(0028). doi: $10.1038 / \mathrm{s} 41562-016-0028$

Maderer, J. (2016). Artificial intelligence course creates AI teaching assistant. Georgia Tech News Center, 9 May 2016. http://www.news.gatech.edu/2016/05/09/artificial-intelligence-course-creates-ai-teaching-assistan

OECD (2016), OECD Science, Technology and Innovation Outlook 2016, OECD Publishing, Paris.

OECD (2017a), Education at a Glance 2017: OECD Indicators, OECD Publishing, Paris. http://dx.doi.org/10.1787/ eag-2017-en

OECD (2017b), OECD Digital Economy Outlook 2017, OECD Publishing, Paris http://dx.doi.org/10.1787/ 9789264276284

Popenici, S. A.D. \& Kerr, S. (2017). Exploring the Impact of Artificial Intelligence on Teaching and Learning in Higher Education

Pravilnik o razpisu za vpis in izvedbi vpisa v visokem šolstvu http://pisrs.si/Pis.web/pregledPredpisa?id= PRAV12769

Reisman, D., Schultz, J., Craword K. \& M. Whittaker (2018). Algorithmic Impact Assessments: A Practical Framework for Public Agency Accountability, April 2018: https://ainowinstitute.org/aiareport2018.pdf

Sagemueller, I. (2017). How Artificial Intelligence Helps Higher Education Management, U-planer, 17.1.2017, https://www.u-planner.com/blog/artificial-intelligence-use-in-higher-education-management

Statistical Office of the Republic of Slovenia: Population projections 2015 by sex and age, Slovenia, 2015 - 2081 , http://pxweb.stat.si/pxweb/Dialog/varval.asp?ma=05U3005E\&ti=\&path=../Database/Demographics/05_po pulation/45_projections/10_05U30_europop/\&lang=1 


\section{Issues in Information Systems}

Volume 19, Issue 4, pp. 96-105, 2018

Tufekci, Z. \& C. Rose. (2016). Interview on Artificial Intelligence,6 July 2016: https://charlierose.com/videos/28424

Vanderbilt, T. (2012). How Artificial Intelligence Can Change Higher Education, Smithsonian Magazine, https:// www.smithsonianmag.com/people-places/how-artificial-intelligence-can-change-higher-education136983766/

Zakon o maturi http://www.pisrs.si/Pis.web/pregledPredpisa?id=ZAKO5100

Zupanc, D., Bren, M. \& G. Cankar (2012). Interno ocenjevanje pri slovenski maturi. Šolsko polje, letnik 23, številka 3/4, str. 113-137, 283-284. URN:NBN:SI:DOC-R6WELTFA from http://www.dlib.si 